\title{
Hands-on or hands-off the perineum at childbirth: A re-appraisal of the available evidence
}

\author{
Angeliki Antonakou ${ }^{1}$
}

Obstetric anal sphincter injuries (OASIS), or third-degree and fourth-degree perineal tears, represent a serious complication of vaginal birth. There are reports that OASIS is a risk factor for the development of anal incontinence ${ }^{1-4}$, with significantly worse bowel symptoms and anorectal function with the higher degree of OASIS 5,6 . In addition, the economic cost of anal incontinence management following OASIS has been estimated to be approximately $£ 1625$ per patient $^{7}$ or $£ 78$ million per annum in the United Kingdom alone ${ }^{8}$.

The current UK based maternity practice at second stage of labour involves two techniques $\left.{ }^{9,10}: \mathbf{1}\right)$ 'hands-on', where one hand of the practitioner applies pressure on the fetal head while the other hand supports the perineum, 2) 'hands-poised', where the hands of the practitioner are poised, ready to apply light pressure on the fetal head to avoid rapid expulsion. Most often, however, this latter technique has been misinterpreted as a 'hands-off technique'.

The Royal College of Midwives (RCM) in 2012, and in line with the NICE 2007 guidance on intrapartum care, has suggested that the available evidence is inconclusive as to whether the 'hands-on' technique reduces the incidence of severe perineal trauma ${ }^{11}$. The RCM 2012 and NICE 2007 recommendations were based on two randomised controlled trials (RCTs), those of McCandlish et al. (1998) in the UK and Mayerhofer et al. (2002) in Austria ${ }^{12,13}$, which have however received heavy criticism from later studies as to the validity of their results and the robustness of their study design and methodology ${ }^{14,15}$.

In the United Kingdom the incidence of OASIS for primiparous women has been reported to have tripled from $1.8 \%$ to $5.9 \%$, over a 12 -year period ${ }^{8}$. In Norway, the OASIS rate has increased from $<1 \%$ in the 1960 s to $4.3 \%$ at the beginning of the past decade ${ }^{16,17}$. A similar increase has been noted in other European countries, with the exception of Finland where the OASIS rate has remained stable at less than $1 \%$ over the past 25 years ${ }^{18,19}$. It is considered that this increase is secondary to the increased incidence of instrumental deliveries, improved training for health professionals and changing maternal-fetal risk factors. Nevertheless, regardless of the above-mentioned factors, the low risk of OASIS in Finland is suggested to be due to the classic 'hands-on' technique of perineal support at birth ${ }^{19,20}$. This hypothesis was tested in Norway in two hospital-based studies (2010 and 2012) that showed a significant decrease of OASIS by $50-70 \% \%^{1,16}$. It is interesting that these two studies were commissioned by the Norwegian Board of Health in 2004 as part of the national strategy to reduce OASIS, since hospitals were heavily criticised for having a high OASIS rate of $4.5 \%$ in 2004 , and were therefore required to implement programs to reduce this.

Following these two studies ${ }^{1,16}$, there was a UK population-based study in 2016 that replicated the study design of the Norwegian studies ${ }^{21}$. This UK study showed that 'hands-on' the perineum during the crowning at second stage reduced the OASIS overall rates by $23 \%$ and the $3 \mathrm{c}$ third degree and 4 th degree tears by $71 \%$. In a recent metanalysis in 2015 of observational studies, it was also shown that there was a significant reduction in the risk of OASIS with manual protection ${ }^{22}$.

At present in the United Kingdom, there is a collaborative project named the OASI Care Bundle Project, which is a collaboration between the professional bodies of the Royal College of Midwives and the Royal College of Obstetricians and Gynaecologists funded by The Health Foundation ${ }^{23}$. The aim of this project is to reduce OASIS through a standardised practice and involves 16 participating maternity units in the UK. The OASI Care Bundle will be applied to all women in the participating maternity units at childbirth and includes communicating with the woman to enable a slow controlled birth of the baby's head, performing a mediolateral episiotomy if and when indicated, and using manual perineal protection for all spontaneous births and all assisted instrumental deliveries. This project has the scientific rigor, sufficient sample size and robust methodology to assess whether 'hands-on' should be the preferred practice or not.

In conclusion, obstetric anal sphincter injuries (OASIS) affect a significant number of women at childbirth every year worldwide. This is a woman's health problem with serious quality of life and long-term adverse health-economic implications. The current evidence is that 'hands-on' manual support of the

\author{
AFFILIATION \\ 1 Department of Midwifery, \\ Midwifery School, 'Alexander' \\ Technological Educational \\ Institute of Thessaloniki, Greece
}

CORRESPONDENCE TO Angeliki Antonakou. Department of Midwifery, Midwifery School, 'Alexander' Technological Educational Institute of Thessaloniki, PC 57400, Greece. E-mail: angelantonakou@gmail. com

\section{KEYWORDS}

perineum, hands-on, handsoff, perineal trauma, OASI Care Bundle Project

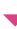

Received: 24 September 2017 Accepted: 13 October 2017 


\section{Editorial}

perineum at birth might reduce significantly the incidence of OASIS. With the implementation of the OASI Care Bundle Project this issue will be finally clarified and midwifery practice in the United Kingdom and internationally will be significantly altered.

\section{REFERENCES}

1. Hals Elisabeth, Øian Pål, Pirhonen Tiina, Gissler Mika, Hjelle Sissel, Nilsen Elisabeth Berge, Severinsen Anne Mette, Solsletten Cathrine, Hartgill Tom, Pirhonen Jouko. A multicenter interventional program to reduce the incidence of anal sphincter tears. Obstet Gynecol. 2016; 116:901-908. doi: 10.1097/aog.0b013e3181eda77a

2. Hirsch Emmet, Haney Elaine I., Gordon Trent E.J., Silver Richard K. Reducing high-order perineal laceration during operative vaginal delivery. Am J Obstet Gynecol. 2008;198:668. doi: 10.1016/j.ajog.2008.02.002

3. Pollack J, Nordenstam J, Brismar S, Lopez A, Altman D, Zetterstrom J. Anal incontinence after vaginal delivery: a five year prospective cohort study. Obstet Gynecol. 2004;104: 1397-1402. doi: 10.1097/01.aog.0000147597.45349

4. Evers Emily C., Blomquist Joan L., McDermott Kelly C., Handa Victoria L. Obstetrical anal sphincter laceration and anal incontinence 5-10 years after childbirth. Am J Obstet Gynecol. 2012; 207:425.e1-6. doi: 10.1016/j.ajog.2012.06.055

5. Radestad I, Olsson A, Nissen E, Rubertsson C. Tears in the vagina, perineum, sphincter ani, and rectum and first sexual intercourse after childbirth: a nationwide follow-up. Birth. 2008; 35:98-106. doi: 10.1111/j.1523-536x.2008.00222.x

6. Roos AM, Thakar R, Sultan AH. Outcome of primary repair of obstetric anal sphincter injuries (OASIS): does the grade of tear matter? Ultrasound Obstet Gynecol. 2010; 36:368-374. doi: 10.1002/uog.7512

7. NICE Guideline (CG49) (2007) Faecal incontinence in adults: management.

8. Gurol-Urganci I, Cromwell DA, Edozien LC, Mahmood TA, Adams EJ, Richmond DH, Templeton A, van der Meulen JH. Third- and fourth degree perineal tears among primiparous women in England between 2000 and 2012: time trends and risk factors. BJOG.2013; 120:1516-1525. doi: 10.1111/1471-0528.12363

9. NICE Guideline (CG55) (2007) Intrapartum care: Care of healthy women and their babies during childbirth.

10. NICE Guideline (CG190) (2014) Intrapartum care for healthy women and babies.

11. Royal College of Midwives (2012). Evidence Based Guidelines for Midwifery- Led Care in Labour: Care of the Perineum.

12. McCandlish Rona, Bowler Ursula, Asten Hedwig, Berridge Georgina, Winter Cathy, Sames Lesley, Garcia Jo, Renfrew Mary, Elbourne Diana. A randomised controlled trial of care of the perineum during second stage of normal labour. Br J Obstet Gynaecol. 1998;105: 1262-1272. doi: 10.1111/j.1471-0528.1998.tb10004.x

13. Mayerhofer K, Bodner-Adler B, Bodner K et al (2002) Traditional care of the perineum during birth: a prospective, randomised, multicenter study of 1076 women. J Reprod Med 47:477-482.

14. Trochez Ruben, Waterfield Malcolm, Freeman Robert M.. Hands on or hands off the perineum: a survey of care of the perineum in labour (HOOPS). Int Urogynecol J. 2011; 22:1279-85. doi: 10.1007/s00192-011-1454-8

15. Jansova Magdalena, Kalis Vladimir, Rusavy Zdenek, Zemcik Robert, Lobovsky Libor, Laine Katariina. Modeling manual perineal protection during vaginal delivery. Int Urogynecol J. 2014; 25:65-71. doi: 10.1007/s00192-013-2164-1

16. Laine Katariina, Skjeldestad Finn Egil, Sandvik Leiv, Staff Anne Cathrine. Incidence of obstetric anal sphincter injuries after training to protect the perineum: cohort study. BMJ Open. 2012; 2(5), e001649. doi: 10.1136/bmjopen-2012-001649

17. Baghestan Elham, Irgens Lorentz M., Børdahl Per E., Rasmussen Svein. Trends in risk factors for obstetric anal sphincter injuries in Norway. Obstet Gynecol. 2010; 116:25-34. doi: 10.1097/aog.Ob013e3181e2f50b

18. Pirhonen JP, Grenman SE, Haadem K, Gudmundsson S, Lindqvist P, Siihola S, Erkkola RU, Marsal K. Frequency of anal sphincter rupture at delivery in Sweden and Finland--result of difference in manual help to the baby's head. Acta Obstet Gynecol Scand. 1998; 77:974-7. doi: 10.1034/j.1600-0412.1998.771005.x

19. Räisänen S, Cartwright R, Gissler M, Kramer MR, Laine K, Jouhki MR, Heinonen S. Changing associations of episiotomy and anal sphincter injury across risk strata: results of a population-based register study in Finland 2004-2011. BMJ Open. 2013; 3:e003216. 


\section{Editorial}

doi: 10.1136/bmjopen-2013-003216

20. Laine Katariina, Pirhonen Tiina, Rolland Rune, Pirhonen Jouko. Decreasing the incidence of anal sphincter tears during delivery. Obstet Gynecol. 2008; 111:1053-7.

doi: 10.1097/aog.0b013e31816c4402

21. Naidu Madhu, Sultan Abdul H., Thakar Ranee. Reducing obstetric anal sphincter injuries using perineal support: our preliminary experience. Int Urogynecol J. 2016; 28:381-389.

doi: 10.1007/s00192-016-3176-4

22. Bulchandani S, Watts E, Sucharitha A, Yates D, Ismail KM. Manual perineal support at the time of childbirth: a systematic review and meta-analysis. BJOG. 2015; 122:1157-65.

doi: 10.1111/1471-0528.13431

23. The OASI Care Bundle Project. Available at: https://www.rcog.org.uk/OASICareBundle (accessed September 2017).

The authors have completed and submitted the ICMJE Form for Disclosure of Potential Conflicts of Interest and none was reported.

\section{FUNDING}

There was no source of funding for this research

\section{PROVENANCE AND}

PEER REVIEW

Not commissioned;

Internally peer reviewed 